\title{
Les Amérindiens face au Covid-19
}

État de l'art et revue de presse

\section{Paul Codjia et Raphaël Colliaux}

\section{CpenEdition} Journals

Édition électronique

URL : https://journals.openedition.org/jsa/19674

DOI : 10.4000/jsa. 19674

ISSN : 1957-7842

Traduction(s) :

Amerindians in the face of Covid-19 - URL : https://journals.openedition.org/jsa/19797 [en] Los Amerindios frente al Covid-19 - URL : https://journals.openedition.org/jsa/19799 [fr]

Os povos indígenas e o Covid-19 - URL : https://journals.openedition.org/jsa/19804 [pt]

Éditeur

Société des américanistes

Édition imprimée

Date de publication : 30 septembre 2021

Pagination : $207-212$

ISSN : 0037-9174

Référence électronique

Paul Codjia et Raphaël Colliaux, "Les Amérindiens face au Covid-19 », Journal de la Société des américanistes [En ligne], 107-1 | 2021, mis en ligne le 30 septembre 2021, consulté le 04 septembre 2022. URL : http://journals.openedition.org/jsa/19674 ; DOl : https://doi.org/10.4000/jsa.19674

Ce document a été généré automatiquement le 4 septembre 2022

Tous droits réservés 


\title{
Les Amérindiens face au Covid-19
}

\author{
État de l'art et revue de presse
}

Paul Codjia et Raphaël Colliaux

1 Ce texte constitue une brève présentation d'une liste de références en construction réunissant des travaux en ligne de divers ordres (textes scientifiques, articles de presse, chaines vidéo, portfolios) qui permettent de témoigner des conditions de vie des Amérindiens durant cette crise sanitaire mondiale. Cette liste, que nous avons classée en différentes sections idoines, est accessible sur le site internet de la Société des américanistes (www.americanistes.org), qui inaugure une chronique entièrement dédiée à la question. Si les coordinateurs de ce travail, en raison de leurs affinités particulières avec ce terrain, se sont d'abord concentrés sur le bassin amazonien, cette liste de références rassemblera à terme des écrits et des matériaux décrivant la situation en temps de pandémie des Amérindiens de l'ensemble du continent américain. 
Fig. 1 - A doença do Covid-19, Jaime Diakara'

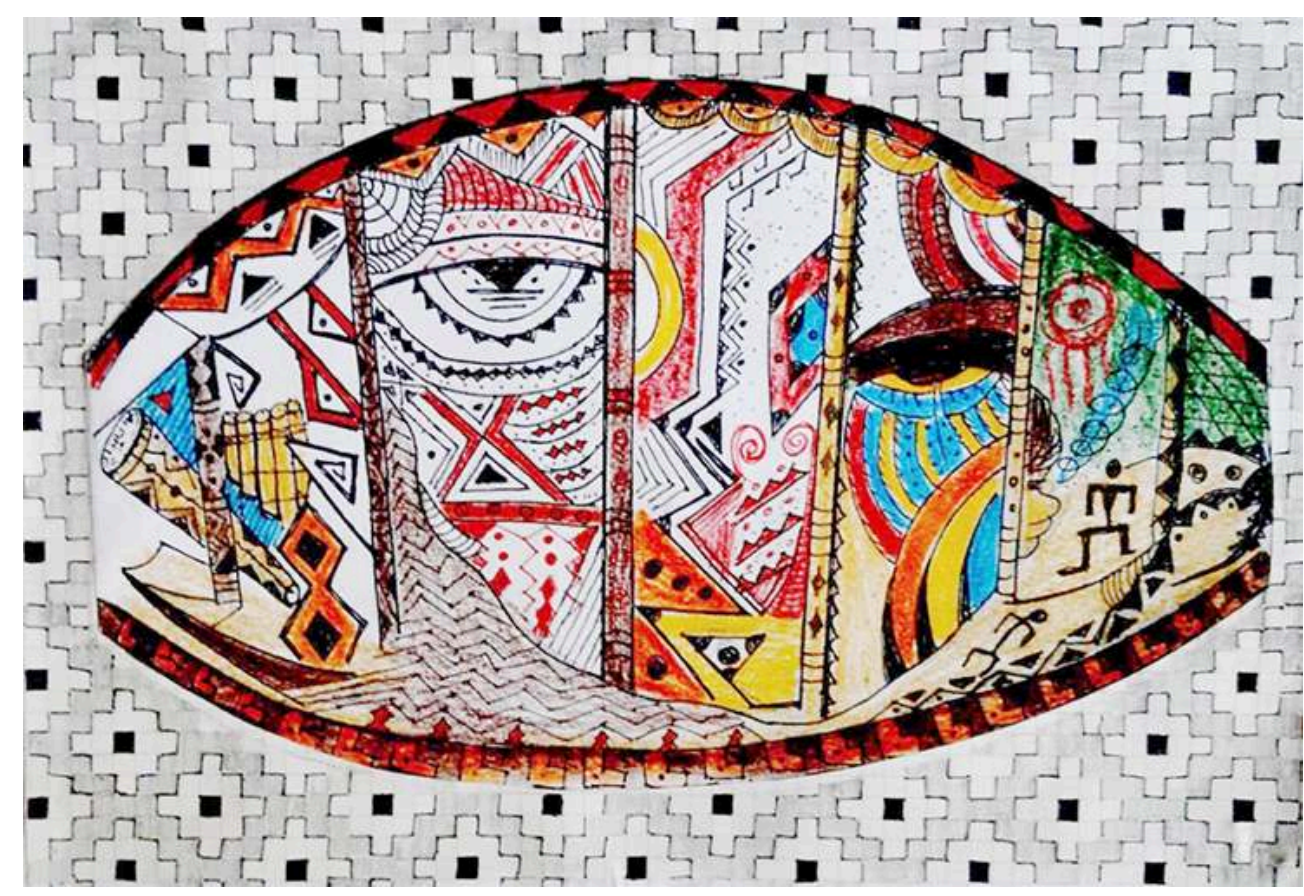

$* * *$

2 Dès avril-mai 2020, de nombreux universitaires, journalistes, leaders politiques amérindiens ou membres d'ONG se sont attelés à documenter l'impact de la pandémie de Covid-19 sur les populations autochtones du bassin amazonien. Que ce soit sous la forme d'articles dans des revues et sur des blogs scientifiques, ou encore dans des journaux de grande diffusion, tous les textes sonnent l'alarme, chacun à leur manière, sur les conséquences sanitaires, sociales, économiques, écologiques, politiques et anthropologiques de la propagation du SARS-CoV-2 dans les basses terres. Il convient ici de saluer la réactivité et les efforts qui ont été d'ores et déjà fournis pour interpeller, mais aussi produire des analyses et des réflexions en des temps records, en vue de rendre visible la situation dramatique dans laquelle se trouvent très souvent ces populations. La pandémie est venue s'ajouter à des contextes de précarité territoriale, de systèmes de santé défaillants et de politiques étatiques trop souvent défavorables aux droits des Amérindiens. Le cas du Brésil sous régime bolsonariste en est très certainement l'exemple le plus tragique.

3 Nous avons réuni dans cette liste de références - non exhaustive - des textes qui offrent un panorama assez large de la diversité des situations et des difficultés que rencontrent les populations amazoniennes au temps du Covid-19. L'objectif de cette compilation est de permettre au lecteur d'identifier des problématiques, d'ouvrir des perspectives de recherche, et de continuer le travail de documentation, de visibilisation et de soutien aux groupes autochtones des basses terres. Contraints de rester derrière leurs écrans d'ordinateur pour éviter de se transformer en vecteurs de la maladie, une très grande part des chercheurs spécialistes de cette région en sont désormais réduits à des échanges sporadiques avec leurs contacts et amis sur le terrain, et à glaner des informations éparses sur les réseaux sociaux ou les médias spécialisés. La présente liste vise à faciliter ces investigations et c'est pourquoi un état de l'art de la littérature scientifique sur le 
Covid-19 en Amazonie côtoie ici une revue de presse, mais aussi des matériaux non analysés, comme une collection de liens renvoyant aux consignes sanitaires traduites en langues amérindiennes. Nous présentons d'abord les articles scientifiques et les numéros spéciaux de revue, puis nous rassemblons les articles journalistiques dans des rubriques différentes en fonction de la thématique qu'ils traitent.

4 En cette période d'isolement, ce sont les méthodologies mêmes de la recherche ethnographique qui sont questionnées par la pandémie, a fortiori pour les chercheurs allochtones. Et c'est peut-être un enseignement important à retenir de ce bilan bibliographique encore incomplet: le contexte sanitaire semble accélérer les collaborations dans les analyses, voire dans le travail même d'écriture, entre universitaires et représentants des peuples autochtones. Mieux encore, un nombre conséquent d'articles répertoriés sont écrits par des universitaires autochtones, provenant en particulier de l'Amazonie brésilienne. En dépit des confinements, les moyens de communication autorisent un travail constant de veille et de collecte d'informations (c'est le cas par exemple des pages Facebook comme https:// www.facebook.com/groups/coronamazon/, administrée par Émilie Stoll et modérée par Ricardo Folhes et Élise Capredon), et ensuite d'échanges et de réflexions conjointes avec des contacts autochtones sur place, bien souvent des leaders politiques.

5 Sur le fond, outre les descriptions souvent chiffrées de la situation épidémiologique, les articles amorcent des réflexions générales sur plusieurs axes de travail que nous pourrions résumer comme suit. D'abord, la thématique centrale, présente dans pratiquement tous les textes, est celle du rapport entre les groupes autochtones, les États et leur système de santé. Les écrits soulignent l'incapacité des États à répondre aux besoins sanitaires des populations autochtones, en raison de politiques de santé inégalitaires, mais aussi, et peut-être plus grave encore, par méconnaissance des réalités sociales, en termes d'infrastructures par exemple, et des pratiques des Amérindiens relatives à la santé. Les mots employés par les interlocuteurs autochtones sont très forts pour décrire cette situation. On oscille entre le champ sémantique de l'abandon, du côté des pays andins, ou celui de l'absence, du côté brésilien, où les peuples autochtones ne se font aucune illusion quant aux intentions du régime de Bolsonaro à leur égard. Faute de ressources institutionnelles efficaces pour protéger leurs corps, les Amérindiens optent pour la protection de leurs territoires.

6 On note ainsi une réaffirmation claire des revendications de souveraineté territoriale, souveraineté paradoxalement renforcée par les recommandations des États andins invitant les groupes amérindiens à fermer et à contrôler l'accès à leur terre. Comme le fait remarquer Irène Bellier dans différentes communications mentionnées ci-dessous, on relève en effet un lien étroit entre la santé des personnes et la "santé » des territoires, lien avant tout de nature nourricière. L'idée revient régulièrement qu'une alimentation produite au sein des territoires autochtones serait une des conditions pour se maintenir en bonne santé, contrairement à la nourriture provenant des villes où sévit en premier lieu le Coronavirus. Cette volonté de protection du territoire se manifeste en particulier dans les luttes qui s'organisent pour freiner les activités de bûcheronnage ou d'orpaillage. En ce sens, et avec peut-être une pointe d'ironie, Gregorio Mirabal, le coordinateur de la Coordinadora de Organizaciones Indígenas de la Cuenca Amazónica (COICA), affirmait récemment : "Tenemos que hacer un proceso de vacunaciones en todos los territorios de la cuenca amazónica con esa vacuna que se llama "gobernanza territorial indígena" y que es lo único que nos puede salvar.» (" Nous devons faire une campagne de vaccination 
dans tous les territoires du bassin amazonien avec le vaccin qui s'appelle "gouvernance territoriale autochtone", le seul qui pourra nous sauver.»)

7 Aussi, on est frappé par le gain de légitimité dont ont bénéficié certaines revendications territoriales et autonomistes amérindiennes, du fait du vide laissé par les États. Dans le même temps, on s'aperçoit que les Autochtones ont été confrontés à une reprise fulgurante des activités extractives - entre autres, le bûcheronnage, l'extraction d'hydrocarbures ou encore les activités minières. Au Pérou, dès le mois de mai 2020, une série de décrets exonérait certains secteurs économiques de normes environnementales contraignantes, et allégeait les mécanismes de consultation citoyenne face aux projets extractifs. Potentiellement, la pandémie augure ainsi un double mouvement : le retrait, d'une part, de la puissance publique et, d'autre part, le redéploiement d'un secteur privé aux multiples visages, dont les activités sont souvent informelles, voire parfois criminelles. Les assassinats de leaders amérindiens et écologistes qui se sont multipliés depuis le début de la pandémie en Amazonie péruvienne et colombienne notamment, rappellent, de manière tragique, que les territoires autochtones sont plus que jamais objets de convoitise.

8 Néanmoins, l'acceptation ou non de ces activités sur les territoires amérindiens fait aussi débat au sein même des populations autochtones, d'autant que la crise sanitaire les a parfois amputés de revenus substantiels. On le voit, la pandémie exacerbe des problématiques anciennes, dont celle de l'action des missionnaires protestants évangéliques dans la région constitue un autre exemple probant. Plusieurs sources suggèrent que les pasteurs profiteraient de la peur suscitée par le virus pour asseoir un peu plus leur influence et donner un nouvel élan à leurs ambitions prosélytes.

Si les intentions missionnaires multiplient les inquiétudes, c'est en particulier au sujet des groupes amérindiens en situation dite d'« isolement volontaire», avec lesquels certains secteurs religieux seraient tentés de forcer le contact - et cela à la faveur de la profonde reconfiguration des dynamiques politiques locales, dont on ne perçoit encore que la face émergée. Depuis au moins le $\mathrm{xvI}^{\mathrm{e}}$ siècle en effet, les populations amérindiennes d'Amazonie ont mobilisé des stratégies d'éloignement pour se prémunir des dangers immunologiques (variole, rougeole, grippes) liés en particulier à la colonisation européenne, mais peut-être aussi issus des zoonoses dont la forêt tropicale est potentiellement porteuse (voir l'article de Stephen Rostain ${ }^{2}$ ). Dans de nombreux cas, cette volonté d'isolement volontaire s'est renforcée au fil des années, à mesure que de nouvelles formes de colonisation apparaissaient et s'intensifiaient (prosélytisme évangélique et catholique, agro-industrie, exploitation d'hydrocarbures, orpaillage, bûcheronnage illégal, trafic de drogue, tourisme), et au sujet desquelles les institutions publiques locales se montraient impuissantes, voire parfois complaisantes. Si, du fait de leur isolement ancien, ces Amérindiens restent extrêmement vulnérables face aux maladies infectieuses et virales, le Covid-19 constitue pour eux un danger considérable que de nombreux observateurs se sont attachés à documenter.

10 Ce thème donne d'ailleurs matière à une réflexion de plus grande envergure sur la notion d'« isolement social ». L'actualité, en effet, a le mérite de renverser la perception de cette pratique comme réflexe primitif et anachronique d'Amérindiens hostiles à la modernité. Tout au contraire, les mesures mondiales prises contre le Covid-19 révèlent, par effet de miroir, combien ces modes de vie amérindiens émergent directement du contexte social et politique - et donc viral - auquel ces populations ont été confrontées, et justifient leur volonté désormais partagée par les États eux-mêmes d'un isolement social 
protectionniste. En ce sens, la littérature montre la permanence, la réactivation voire la légitimation, sous l'effet de la pandémie, des stratégies d'éloignement volontaire dans cette région du monde, et au-delà.

11 Aussi, ces textes ne se contentent pas de dresser des tableaux sombres de la situation. Ils mettent aussi en lumière les formidables ressources organisationnelles, politiques et sanitaires que les Amérindiens mobilisent pour se protéger, faire face et tenter d'enrayer les dynamiques de transmission du virus. Des initiatives autochtones fleurissent pour faire valoir les savoirs et les pratiques médicales locales, et pour réclamer une véritable interculturalité dans les politiques sanitaires de l'État.

L'épidémie apparaît ainsi comme un «fait social total » en contexte postcolonial, un nœud dans lequel entrent en friction jusqu'à des pratiques du deuil et des considérations eschatologiques divergentes. Bruce Albert alerte en ce sens sur la tragédie que vivent les Yanomami privés du corps de leurs proches malades décédés, incinérés par les services sanitaires pour éviter les contagions. La liste de références donne alors à voir une " situation épidémique » - pour paraphraser Georges Balandier - qui met plus que jamais en relation l'ensemble des acteurs locaux : les populations amérindiennes diversement sédentarisées, les multiples colons, les entreprises privées, les institutions publiques, aussi bien que l'agent viral.

\section{Liste de références disponible sur le site internet de la Société des américanistes}

13 http://www.americanistes.org/fr/category/chroniques_fr/amerindiens-face-aucovid-19_fr/

\section{Sommaire des rubriques}
1. Travaux à caractère scientifique
2. Chroniques amérindiennes
3. Pratiques thérapeutiques autochtones
4. Amérindiens urbains et Coronavirus
5. Activités extractives et pandémie
6. Les missionnaires évangéliques
7. Les populations amérindiennes en « isolement volontaire »
8. Reportages photo/Portfolios
9. Informations institutionnelles
10. Consignes de prévention en langues autochtones 


\section{NOTES}

1. Jaime Diakara est anthropologue et artiste peintre desana (groupe de l'ensemble linguistique tukano, Amazonie brésilienne). L'auteur a réalisé cette œuvre après avoir été atteint par la maladie. Il a souhaité exprimer ainsi les symptômes qu'il avait éprouvé. Il explique que la partie gauche représente la contamination par le SARS-CoV-2 et comment le virus a pris possession de son corps. Dans la partie de droite, apparaissent les silhouettes de son père et de ses aïeux qui, grâce à leurs connaissances ancestrales des plantes médicinales, l'ont aidé à vaincre le virus.

2. «Amazonie, une histoire sans geste barrière » [en ligne], 16 décembre 2020 https:// covidam.institutdesameriques.fr/amazonie-une-histoire-sans-geste-barriere/, consulté le $25 / 05 / 2021$.

\section{AUTEURS}

\section{PAUL CODJIA}

McGill University - Fondation Fyssen - IFEA, membre du projet Amaz (ANR-17-CE41-0013)

RAPHAËL COLLIAUX

IFEA - PUCP - Fondation Fyssen, membre du projet Amaz (ANR-17-CE41-0013) 